\title{
Where is Archives of Plastic Surgery Now? And Where is It Heading?
}

\author{
Jeong Tae Kim \\ Editor-in-Chief, Archives of Plastic Surgery
}

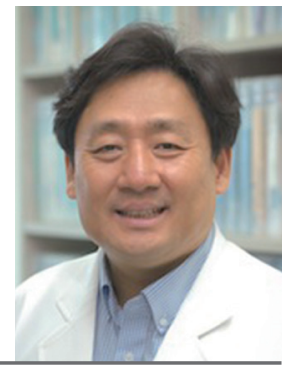

The Korean Society of Plastic and Reconstructive Surgeons (KSPRS) was founded in 1966, and began to circulate the Journal in the Korean-language from 1974. The Society members had long desired to communicate with the rest of the world, and found the language issue to be the limiting factor. In 1996, a forward-thinking editor-in-chief had pushed for an English version of the Korean Journal of Plastic and Reconstructive Surgery (KJPRS), but this effort was not sustainable from the mere fact that very few manuscripts were being prepared in English at the time (Fig. 1). By 1998, it was clear that the fledgling English journal was not a viable enterprise, and for the time being, Korean plastic surgeons and researchers continued to submit their research findings in the native language.

The matter, however, continued to be reviewed at each of the annual KSPRS Board meetings throughout the 2000's. I was elected to be the chief editor of the KJPRS in November 2010, with the ambitious goal of re-starting an English journal to be circulated among Korean and international scholars.

It took all of 2011 to overcome the logistics of starting a whole new journal in a new language, and the very first issue of Archives of Plastic Surgery (APS) was published in January of 2012 [1]. Since the inception, the editorial committee, staff, and I have made a concerted effort in improving the quality despite the limited finances alloted for the activity. Considering the state of our Journal-healthy and growing in volumes-I would like to take this opportunity to express our gratitude to the authors for the quality of articles submitted, to the 124 Korean and 41 international reviewers who have stimulated a discussion on the ideas presented in each of these articles, and to the readers of Journal without whom these ideas would remain isolated and soon forgotten.
To produce a worthy academic journal, APS has solicited review papers from prominent surgeons both within and outside of Korea. Ethical standards are higher, with strict noresubmission policy for manuscripts containing plagiarized elements found via CrossCheck reference program. Written permissions are now a strict requirement for inclusion of patient photographs. In addition, figures and illustrations adhere to a more consistent format from the cover to the last page. Research articles supported with academic funds have especially been welcomed.

We have made a concerted effort to invite manuscripts from the international community, with a specific focus on our Asian counterparts. The editorial committee have attended many international conferences to promote the Journal, and have signed

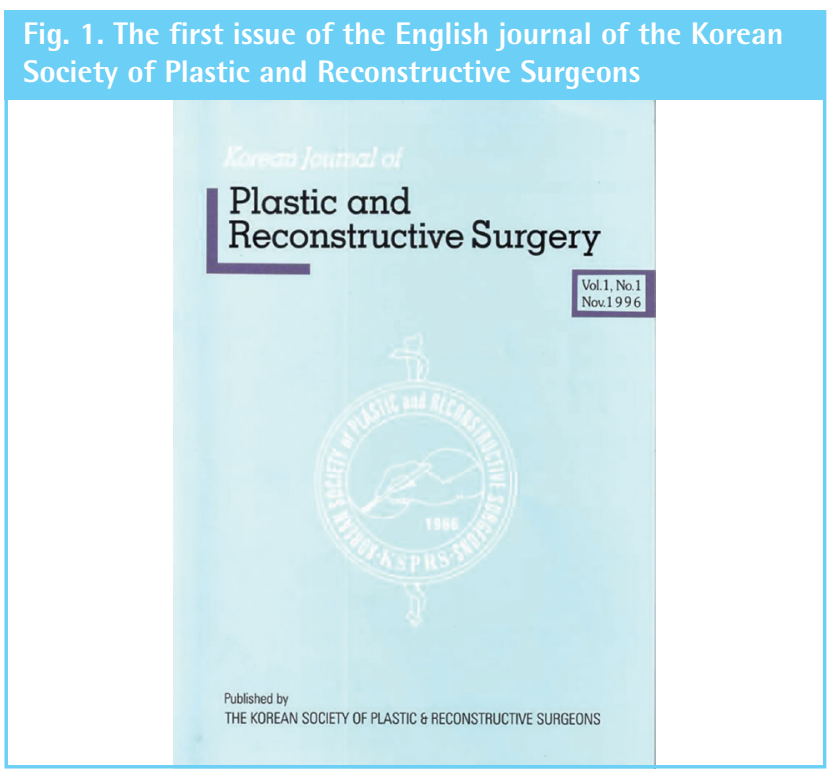

Copyright $(\subseteq 2014$ The Korean Society of Plastic and Reconstructive Surgeons

This is an Open Access article distributed under the terms of the Creative Commons Attribution Non-Commercial License (http://creativecommons.org/

licenses/by-nc/3.0/) which permits unrestricted non-commercial use, distribution, and reproduction in any medium, provided the original work is properly cited. 
a mutual agreement with Plastic and Reconstructive Surgery Global Open (Fig. 2). For more than a year now, articles published in APS are indexed by many of the academic search engines, including PubMed Central. Currently, our email subscribership encompasses approximately ten thousand of plastic surgeons around the world. More recently, we have been gearing up for

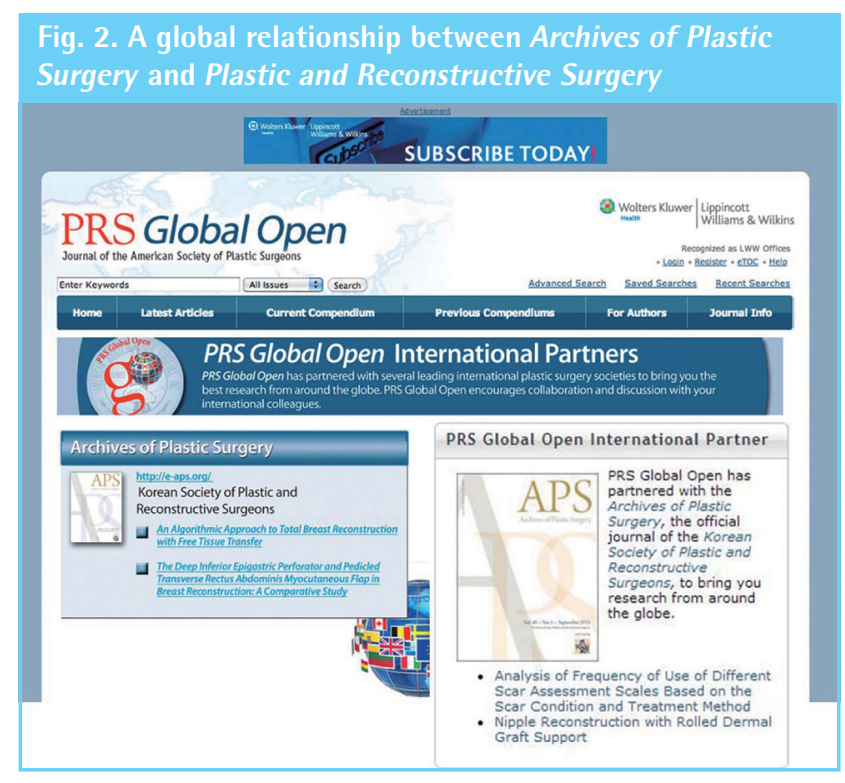

the official journal proposed for the Asia Pacific Section of International Federation of Plastic Reconstructive and Aesthetic Surgery.

The international outreach effort is evident in the increasing number of international submissions over the past two years. In our first year, 2012, just 22 of the 192 total submissions had come from outside of Korea (11.5\%). However, this figure underwent a dramatic increase to 126 submissions from international authors, out of the 303 total (42\%). This increase in international submissions was accompanied by a concomitant increase in the number of countries from which these manuscripts originated (Fig. 3).

In Korea, as elsewhere, the SCI indexed is an important litmus test for an academic journal, and we are sensitive to the needs of academicians who benefit from publishing their scientific work in such journals. Though impact factor (IF) for APS will not be available until 2015, our recent analysis of data from Scopus and Web of Science has revealed a high number of citable articles and expect IF to increase rapidly $[2,3]$. The most significant role the Journal plays is appreciable by the fact that APS is the only English plastic and reconstructive surgery journal in east of Asia.

The definition of what constitutes a citable article continues to change, and the total number of articles published through

\section{Fig. 3. Manuscript submissions to Archives of Plastic Surgery, by country (2013-2014 May)}

Since 2013, a total of 174 papers from 32 countries, excluding Korea, have been submitted for review. This is a significant increase compared to the 22 papers submitted from 12 countries in 2012. Among them, 74 articles (red) were sent from 12 Asian countries excluding Korea (7 articles from 3 Asian counties in 2012).

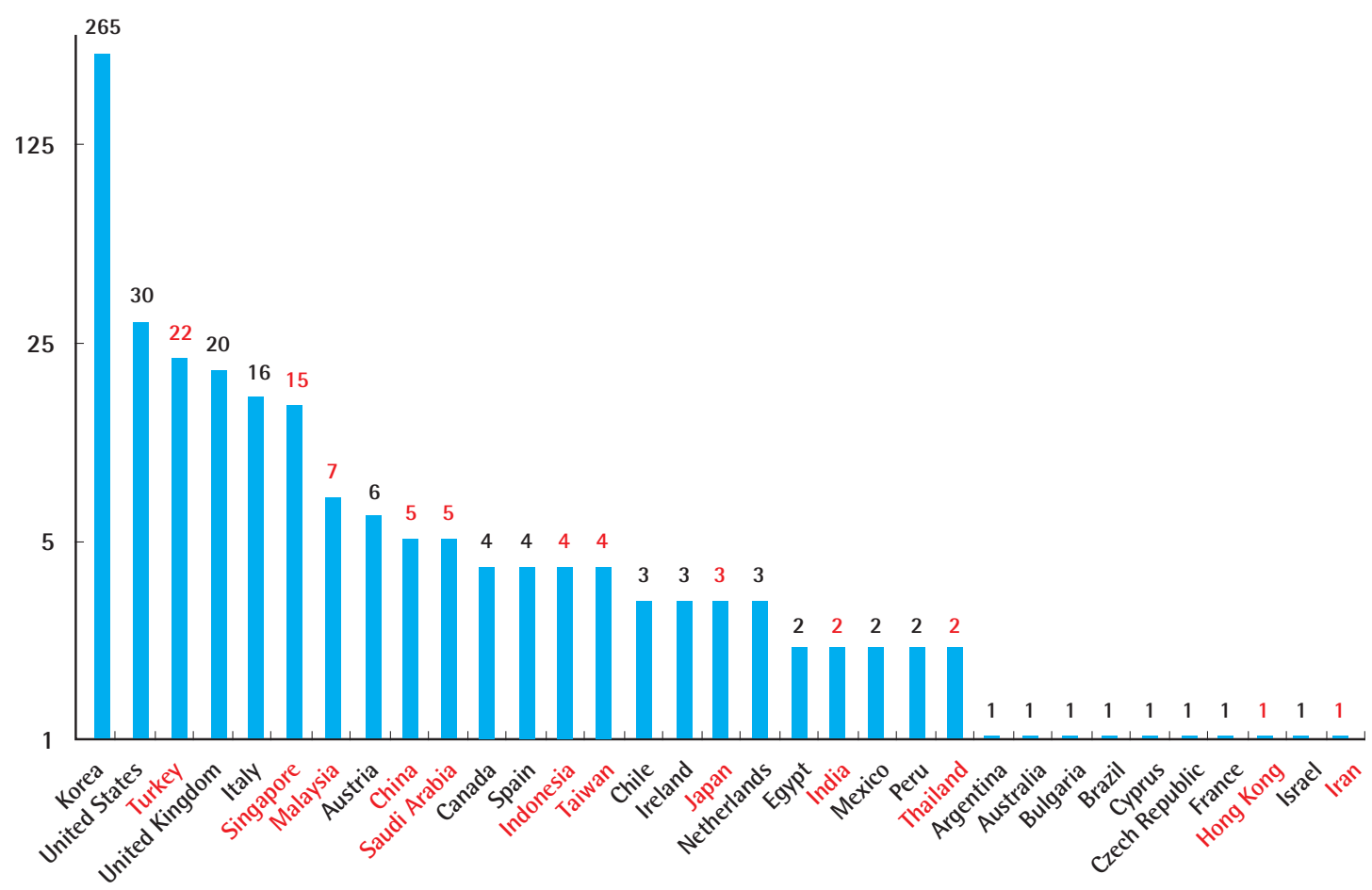


the Journal is hard to estimate for the rest of the current calendar year. However, our current estimates place the IF in a range between 0.6 to 0.9 based on data of Scopus and Web of Science $[2,3]$. Considering that Korean plastic surgery researchers have published 256 articles in 2012 and 103 articles so far this year in relevant $\mathrm{SCI}(\mathrm{E})$ journals [3], we expect that this trend will lead to a greater number of APS articles being cited.

The future of Journal should not be weighed against the indicators above mentioned. Rather, it should be evaluated by the quality of the scientific works submitted, fairness and promptness of the review process, and the up-to-date information made available to the readers. To achieve these goals, we have been closely watching the manuscript review process. Currently, a 3-person peer review process takes an average of 70.4 days (60.5 days and 74.1 days for rejected and accepted manuscripts, respectively), and we are striving to bring quality articles to the readers as soon as possible. In 2013, the rejection rate had increased to 27.4 percent, and this is expected to further increase, to around 40 percent.

To further improve the quality of the Journal, the number of editorial members was expanded to 46, among whom 22 international members live across 5 separate continents. We expect the proportion of international members to continue to grow for the committee.

All of these strategies have increased the number of manuscripts submitted from countries other than Korea. Since 2013, a total of 174 papers from 32 countries, excluding Korea, have been submitted for review (Fig. 3). In addition, our open access policy makes available the contents of each and every article at no cost to the readers. We intend to continue to develop and maintain our relationship with various international plastic sur- gery communities through our involvement in various academic conferences in Korea and other Asian countries.

Along with Korean wave (Hallyu) in Asia, South Korea has become and continues to be the plastic surgery mecca in the Pacific Asia. It is our hope that Archives of Plastic Surgery will find its place as an examplary journal within the field and that the Journal would provide a medium through which Asian plastic surgeons could share and improve the art of the discipline. Through the plastic surgery APS Asian academic exchanges, and spread the hope.

\section{REFERENCES}

1. Kim JT. Evolution to a renowned international journal. Arch Plast Surg 2012;39:1-2.

2. Scopus. Lists of APS article quted in SCI(E) (2012-2013) [Internet]. Oxford: Elsevier B.V.; c2014 [2014 Jul 1]. Available from: www.scopus.com.

3. Web of science [Internet]. Philadelphia: Thomson Reuters; c2014 [cited 2014 Jul 1]. Available from: http://wokinfo. $\mathrm{com} /$.
Correspondence: Jeong Tae Kim

Department of Plastic and Reconstructive Surgery, Hanyang University Medical Center, 345 Wangsimni-gil, Sungdong-gu, Seoul 133-792, Korea

Tel: +82-2-2290-8560, Fax: +82-2-2295-7671, E-mail: jtkim360@gmail.com

No potential conflict of interest relevant to this article was reported.

Received: 25 June 2014 • Revised: 29 June 2014 • Accepted: 1 July 2014 pISSN: 2234-6163 • elSSN: 2234-6171

http://dx.doi.org/10.5999/aps.2014.41.4.309 • Arch Plast Surg 2014;41:309-311 